\title{
CORRIGENDUM
}

\section{Anticipating the perceived risk of nanotechnologies}

Terre Satterfield, Milind Kandlikar, Christian E. H. Beaudrie, Joseph Conti and Barbara Herr Harthorn

Nature Nanotech. 4, 752-758 (2009); published online: 20 September 2009; corrected online: 29 November 2009.

In the version of this Article originally published, the data from ref. 50 used in the meta-analysis and plotted in Fig. 2 were incorrect because these data were subsequently corrected in ref. 51. This mistake does not change any of the conclusions of the paper. An error also occurred in plotting the data from ref. 40 in Fig. 2, but the correct data were used in the rest of the paper. Figure 2 (including caption) and the first two sentences of the paragraph beginning "In the nine surveys" on page 754 of this Article have been amended accordingly in the HTML and PDF versions of the Article. 